\title{
Climate Change: the Contribution of Telecommunications
}

\author{
Ewan SUTHERLAND \\ Research Associate, LINK Centre
}

\begin{abstract}
Global targets for reductions in green house gas emissions require that all economic sectors take stock and then act to limit and to reduce their contributions to climate change. Telecommunications is no exception and while it can help other sectors make savings, the expansion of and growing intensity of use greatly increases the attributable emissions. These arise from a wide range of inputs, including travel and transportation, energy to power and to cool equipment. While reporting at the level of corporations has improved, it is neither consistent nor complete. For consumers and businesses there are almost no data on the various services they buy that might inform their own decision making and their own reporting of emissions.
\end{abstract}

Key words: climate change, energy efficiency, green house gases, telecommunications.

W

ith national political leaders agreeing targets for reductions in the emissions of Green House Gases (GHGs) it is essential for all industries to evaluate their performance and to be able to show that they are making cost effective and proportionate contributions to those reductions. Many of the efforts in the Information and Communication Technologies (ICT) sector have focused on use to help other sectors, for example, through "smart" meters or "smart" infrastructure. However, it is also important to understand the GHGs associated with telecommunications equipment and services in order to ensure that any potential increases from growth in use or increase in the intensity of use are brought under control and overall emissions reduced in absolute terms or, possibly, in proportion to the levels of use. The European Commission (EC, 2009) has already called for a "decarbonisation" of the ICT sector, with measurable and verifiable reductions in energy intensity and carbon emissions.

The paramount questions are the scale of the current emissions, the short term trends and the identification of means to reduce GHGs, together with an evaluation of the associated economic costs and trade-offs. The first challenge is to assess the data that are presently available and to identify the requirements for additional data to support policy-making by

COMMUNICATIONS \& STRATEGIES, no. $76,4^{\text {th }}$ quarter 2009, p. 61. 
governments and organisations, plus decision-making by households and individuals. Associated with this, is a need for scenarios for changes in future use and emissions in order to be able to assess a range of options.

This paper examines the nature and scale of the effects of telecommunications on climate change. Existing tools for environmental management and the reporting of GHGs and energy efficiency are then examined. The issues for the telecommunications sector are considered, both in terms of their scale and the likely bottlenecks.

\section{- Climate change}

The warming of the climate is now unequivocal, observed in increased average air and ocean temperatures, widespread melting of snow and ice, plus the rising average sea level (IPCC, 2007). Most of the observed increase in temperatures since the middle of the 20th century is very likely due to the increase in concentrations of GHGs caused by the activities of human beings.

Figure 1 - Global anthropogenic emissions $\left(\mathrm{CO}_{2}-\mathrm{e}\right)$

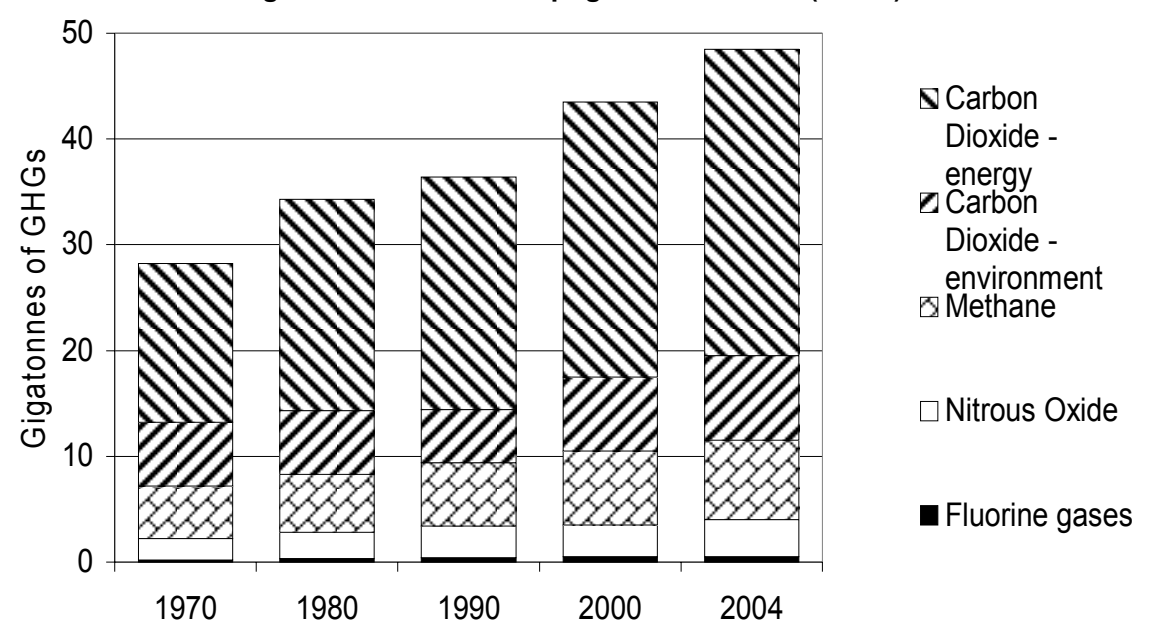

The IPCC estimates that annual emissions rose from 29 to 49 Gigatonnes (Gt) between 1970 and 2004 (see Figure 1). The growth of emissions continued in 2005, but with some changes due to improved methodologies (HERZOG, 2009). While the average emission of someone in 
North America was over 25 tonnes $\mathrm{CO}_{2}$-e per annum, an average African was responsible for less than 5 tonnes. At the national level there are enormous variations, largely related to levels of economic development, while for individuals there are variations caused by differences in incomes and lifestyles. Similarly, economic sectors contribute to quite different extents, with ICTs estimated to contribute about 2 to 2.5 per cent of emissions in 2007 of which telecommunications is about one third (GARTNER, 2007, Bio-intelligence, 2008). The various gases have quite different green house effects - their global warming potentials - represented as an equivalence to Carbon Dioxide or $\mathrm{CO}_{2}$-e (see Table 1).

Table 1 - GHGs in telecommunications

\begin{tabular}{|l|l|l|}
\hline \multicolumn{1}{|c|}{ Name } & \multicolumn{1}{|c|}{$\mathrm{CO}_{2}-\mathrm{e}$} & \multicolumn{1}{c|}{ Sources in telecommunications } \\
\hline Hydrofluorocarbons (HFCs) & 11,700 & refrigerants, propellants \& cleaners \\
\hline Sulphur Hexafluoride $\left(\mathrm{SF}_{6}\right)$ & 23,900 & electrical insulation \\
\hline Perfluorocarbons (PFCs) & 6,500 & refrigerants \& fire suppression systems \\
\hline Nitrous Oxide $\left(\mathrm{N}_{2} \mathrm{O}\right)$ & 310 & vehicle engines \& power generation \\
\hline Methane $\left(\mathrm{CH}_{4}\right)$ & 21 & - \\
\hline Carbon Dioxide $\left(\mathrm{CO}_{2}\right)$ & 1 & vehicle engines \& power generation \\
\hline
\end{tabular}

Thirty-seven developed countries made commitments under the Kyoto Protocol to limit and to reduce their GHG emissions from 2008 to 2012. Negotiations are underway to set targets for the next period, due to be completed at the Conference of the Parties in Copenhagen at the end of 2009 (COP, 2009). These are national commitments, set in terms of percentages of $\mathrm{CO}_{2}$-e emissions against a reference date of 1990 for which governments must devise the implementation measures. The Bali Action Plan recognized the need for deep cuts in emissions, calling for "measurable, reportable and verifiable" mitigation of emissions for developed countries and "nationally appropriate" mitigation for developing countries (WITOLEAR, 2007).

Governments face a challenge, especially as their economies emerge from recession, to achieve their commitments without adversely affecting national competitiveness and future economic growth. One concern is that tight controls might cause the displacement of existing or future business activities to countries with less strict controls. They must reconcile unavoidable goals for the reduction of emissions, with ensuring the continuing creation of jobs and sustaining economic growth, while balancing the interests of and spreading the burden across the different economic sectors. 


\section{- The effects of ICTs on climate change}

ICTs are in the middle of the economic value chain, taking inputs from manufacturers of components and materials with "embedded" emissions from the manufacturing processes and transportation, using energy from fossil fuels and other sources, then selling services to organizations as inputs to their goods and services and to individuals for their personal lifestyles. The attribution and accounting of any particular increase or decrease in emissions is not easily made, often with conflicting claims for the savings and fewer claims for the emissions.

All of the GHGs are used in telecommunications to differing extents. The fluorine gases, with the highest multipliers, are used in a range of inputs, notably in air-conditioning and cooling systems for offices, exchanges, base stations and street cabinets. They are also present in systems to extinguish fires, protecting critical infrastructure. A range of very powerful fluorine gases are used in the manufacture of semiconductors, embedded in all telecommunications equipment. Some chemicals which damage the ozone layer have been replaced, though still with gases which have GHG effects. Consequently, some use of fluorine compounds remains unavoidable and even with improvements, for example, to the sealing of systems, there will be some loss to the atmosphere which must be accounted for.

There is a substantial volume of transport of goods and persons, for direct services, operations sales and executives. For example, Telstra has the largest vehicle fleet in Australia and ITU Telecom World 2009 brought together hundreds of senior government and industry figures, most of whom flew to Geneva. In total, business travel and service delivery represent substantial GHG emissions.

The Global e-Sustainability Initiative (GeSI) estimated the 2002 GHG emissions from ICTs, including telecommunications, and made a forecast for 2020 (see Table 2) (Climate Group, 2008). The very substantial growth suggests that the focus of attention for reductions and efficiency gains should be on fixed broadband in developed countries and on mobile telecommunications in developing countries. The growth in the mobile sector is being driven by the expanding customer base, which GeSI assumed would rise from 1.1 billion to 4.8 billion connections, a figure that may prove conservative. The per capita per annum emission figures of $50 \mathrm{~kg}$ in 2002 and $37 \mathrm{~kg}$ in 2020, indicate an expectation of a very significant improvement in performance, about $1.5 \%$ per annum. 16 of the 18 Megatonnes attributable to devices are due to mobile phones, of which 13 are from use 
and the remainder from manufacture and distribution. This was forecast to rise to 22 Megatonnes in 2020, of which 10 would be due to use, a reduction that was to be enabled by significantly improved power consumption.

Table 2 - The global footprint of ICTs (Megatonnes of $\mathrm{CO}_{2}$-e)

\begin{tabular}{|c|l|l|l|}
\cline { 2 - 4 } \multicolumn{1}{c|}{} & 2002 & 2020 & CAGR \\
\hline PCs and peripherals & 247 & 643 & $5.4 \%$ \\
\hline Data centres & 76 & 259 & $7.0 \%$ \\
\hline Telecommunications & 66 & 179 & $5.7 \%$ \\
\hline Mobile & 64 & 70 & $0.5 \%$ \\
\hline Fixed narrowband & 4 & 49 & $15.0 \%$ \\
\hline Fixed broadband & 18 & 51 & $6.0 \%$ \\
\hline Devices & 151 & 349 & $4.8 \%$ \\
\hline Sub-total & $\mathbf{4 7 4}$ & $\mathbf{1 2 5 1}$ & $\mathbf{5 . 5 \%}$ \\
\hline Total ICTs & & & \\
\hline
\end{tabular}

However, the operators were reporting figures of 5 to $30 \mathrm{~kg}$ in 2007 , significantly below the GeSI estimate (see Figure 2). Even the range of values is wider than would be suggested by variations in operational practice. For example, an operator in a densely populated country using power from hydro-electric sources will have a very different footprint from one in a country with coal-powered generation and with a dispersed rural population. In some developing countries there is a worst case scenario of operators running tankers of diesel to supply individual base stations at each of which electricity is generated.

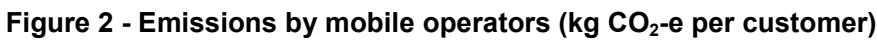

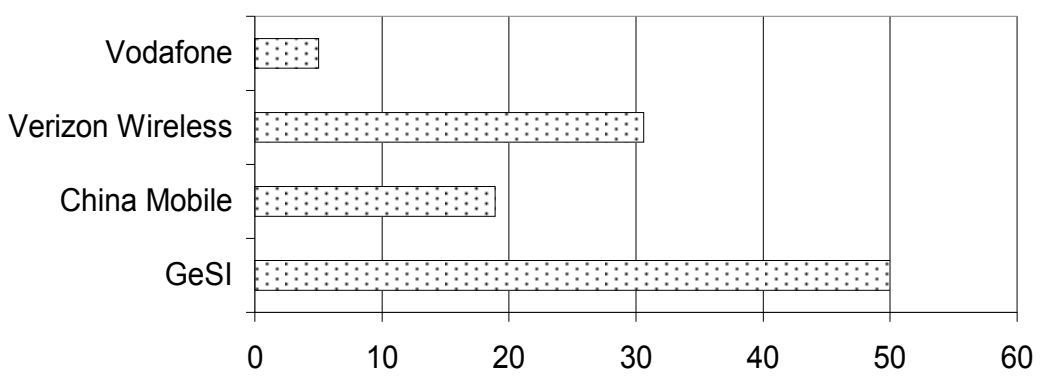

Forecasts for the energy consumption of mobile telecommunications are complicated by the evolution from a voice and SMS service to mobile broadband and by the gradual migration from $2 G$ to $3 G$ to LTE. None of these processes is well understood or easily predicted. Efficiency gains will require considerable flexibility on the part of manufacturers and operators, as patterns of use of mobile broadband emerge and the emissions, for 
example, of upgrading backhaul are taken into account. In addition to the energy used by the operator there is the substantial use of domestic electricity to power the widening range of consumer electronic devices, an increasing number of which are connected to networks (IEA, 2009). This now accounts for a significant part of residential electricity, in part because of the success of campaigns to reduce the power used in heavy appliances. There are growing opportunities to use renewable power sources to power some devices, notably photo-voltaics. The same technologies are also a vital means to recharge devices in parts of the world where there may be no mains electricity or where it is unreliable (GSMA, 2009).

A first step towards limiting and reducing emissions will be to increase the use of certified renewable energy sources, such as hydro-electric power, and the use of wind turbines and photo-voltaic panels to generate the power needed for microwave relay stations and wireless base stations. For example, Telstra has over ten thousand sites powered by photo-voltaic panels. Telenor breaks down its energy consumption as 72 per cent from electricity, 23 per cent from petrol, diesel and other engine fuels, and 5 per cent from district heating. Of that 67 per cent is used for network operations, 20 per cent for offices, while 13 per cent is travel by car and plane. It uses one comparatively unusual source, in that half of the energy required for its buildings comes from heat pumps in the sea. In winter these provide heating and in summer cooling. In Hungary it uses terrestrial heat pumps, 100 metres below the surface

Once the benefits from these approachs have been fully achieved, which will take some years, it will be necessary to deploy devices, networks, protocols and services with increased energy efficiency. Thereafter, the remaining emissions will have to be off-set, for example, using the Clean Development Mechanism (CDM).

\section{Voluntary reporting}

Over the last few years operators have become much more informative on environmental issues, predominantly as Corporate Social Reporting (CSR) rather than in mainstream accounts and annual reports. Of the ICT firms listed in the USA, the number using key climate change expressions in their financial reports has risen significantly, but remains very low compared to other sectors (DORAN, 2009). 
The variations and inconsistency make comparisons very difficult and, arguably, impossible. This is complicated by the use of different indicators including:

- only $\mathrm{CO}_{2}$ emissions (in tonnes);

- all GHG emissions (in $\mathrm{CO}_{2}$-e tonnes);

- $\quad$ energy used (kWh, Joules and oil in kilograms and litres) and

- energy generated or purchased from renewable energy sources (kWh).

Table 3 shows the total emissions reported by some leading operators. It is important to note that these are not based on the same definitions and are, mostly, unaudited. The inconsistencies between the emissions and the volumes of their business suggest that the relative performances of operators cannot be derived from these data. For example, Deutsche Telekom warns that its apparently high level of reporting is due to the use of specific methodology, one that includes more of the inputs. It offset a substantial part of its emissions by buying certificated renewable electrical energy. At least two operators are purchasing substantial quantities of electricity from nuclear power generation, while this does not give rise to significant GHG emissions it may be of concern to some customers on wider environmental issues.

Table 3 - Total emissions by operators (tonnes of $\mathrm{CO}_{2}-\mathrm{e}$ )

\begin{tabular}{|l|l|l|}
\hline \multicolumn{1}{|c|}{ Operator } & \multicolumn{1}{c|}{2007} & \multicolumn{1}{c|}{2008} \\
\hline AT\&T California & 676,505 & 598,053 \\
\hline BT & 680,000 & 680,000 \\
\hline Cable \& Wireless & 113,157 & 160,000 \\
\hline China Mobile & $6,900,000$ & $7,900,000$ \\
\hline Deutsche Telekom & $1,885,318$ & - \\
\hline France Telecom & $1,209,284$ & - \\
\hline Korea Telekom & 714,869 & 874,116 \\
\hline NTT & $3,776,000$ & $3,600,000$ \\
\hline Optus & 252,278 & 309,080 \\
\hline SK Telecom & 358,097 & 389,427 \\
\hline Telenor & 604,767 & 727,935 \\
\hline Telstra & $1,390,306$ & $1,500,803$ \\
\hline Verizon & $6,200,000$ & $6,271,000$ \\
\hline Vodafone $\left.{ }^{*}\right)$ & $1,373,000$ & $1,310,000$ \\
\hline Total & $\mathbf{2 6 , 1 3 3 , 5 8 1}$ & $\mathbf{2 7 , 4 1 5 , 0 1 6}$ \\
\hline
\end{tabular}

$\left(^{*}\right)$ Excludes some 1.9 million tonnes estimated for emissions in India.

$\ddagger$ assumes 2008 figures for Deutsche Telekom and France Telecom are the same as in 2007. In total these firms represent less than one fifth of the figure suggested by GeSI for the emissions of the global telecommunications 
industry. The difference seems likely to be explained by under-reporting rather than over-estimation, the likely causes being a failure to include some of the GHGs associated with purchased inputs. For example, AT\&T California restated its 2007 emissions following a study it conducted.

Table 4 - U.S.A. EPA Climate Leaders - ICT industries

\begin{tabular}{|c|c|}
\hline Name & GHG emission reduction \\
\hline \multicolumn{2}{|r|}{ Semiconductors } \\
\hline Advanced Micro Devices & $\begin{array}{l}\text { by } 33 \text { percent per manufacturing index from } 2006 \text { to } 2010 \text {, } \\
\text { having already reduced global GHG emissions by } 53 \text { percent } \\
\text { per manufacturing index from } 2002 \text { to } 2006 \text {. }\end{array}$ \\
\hline Applied Materials & by 20 percent from 2006 to 2012 . \\
\hline Fairchild Semiconductor & by 30 percent per manufacturing index from 2003 to 2010 . \\
\hline Freescale Semiconductor & under development. \\
\hline Intel Corporation & by 30 percent per production unit from 2004 to 2010 . \\
\hline ST Microelectronics & by 50 percent per manufacturing unit from 2000 to 2010 . \\
\hline NVIDIA Corporation & $\begin{array}{l}\text { by } 9 \text { percent per square foot of non-data center space and } 9 \\
\text { percent in PUE for data centers from } 2007 \text { to } 2012 \text {. }\end{array}$ \\
\hline \multicolumn{2}{|r|}{ Manufacturing } \\
\hline Agilent Technologies & by 10 percent from 2006 to 2011 . \\
\hline Dell Inc. & $\begin{array}{l}\text { by } 15 \text { percent per dollar revenue from } 2007 \text { to } 2012 \text {, and to } \\
\text { achieve net zero global GHG emissions by } 2008 \text { and maintain } \\
\text { that level through } 2012 \text {. }\end{array}$ \\
\hline IBM & $\begin{array}{l}\text { by } 7 \text { percent from } 2005 \text { to } 2012 \text {. IBM achieved its initial goal } \\
\text { by reducing total global energy-related GHG emissions by an } \\
\text { average of } 6 \text { percent per year and PFC emissions by } 58 \\
\text { percent from } 2000 \text { to } 2005 \text {. }\end{array}$ \\
\hline Xerox Corp. & $\begin{array}{l}\text { by } 25 \text { percent from } 2002 \text { to } 2012 \text {. Xerox achieved its initial } \\
\text { goal by reducing total global GHG emissions by } 18 \text { percent } \\
\text { from } 2002 \text { to } 2006 \text {. }\end{array}$ \\
\hline \multicolumn{2}{|r|}{ Telecommunications } \\
\hline Cisco Systems & by 25 percent from 2007 to 2012 . \\
\hline Sprint & by 15 percent from 2007 to 2017 . \\
\hline \multicolumn{2}{|r|}{ Communications } \\
\hline Nortel & by 20 percent from 2007 to 2012 . \\
\hline \multicolumn{2}{|r|}{ Software \& Manufacturing } \\
\hline Sun Microsystems & $\begin{array}{l}\text { by } 20 \text { percent from } 2007 \text { to } 2012 \text {. Sun Microsystems } \\
\text { achieved its initial goal by reducing its total U.S. GHG } \\
\text { emissions by } 23 \text { percent between } 2002 \text { and } 2007 \text {. }\end{array}$ \\
\hline
\end{tabular}

Detailed reporting by operators appears to be concentrated in countries that have made commitments under the Kyoto Protocol. Presumably this 
reflects the perception that obligations will ultimately be imposed on them by national governments. For example, some large operators, such as América Móvil, Etisalat, Millicom and Zain have not reported their GHG emissions ${ }^{1}$.

A significant number of operators have provided information in response to requests from the Carbon Disclosure Project (CDP). This is an effort by investors to assess the risks and opportunities associated with companies in which they might invest, including the effects of any caps on emissions. Some firms supplied information but declined to have it published, while others simply did not reply. Qwest responded: The financial impact of proposed future mandatory regulations requiring $\mathrm{GHG}$ emission inventories of all of our equipment could impose a measurable administrative burden on Qwest, however without a commensurate benefit to the environment since our contributions of GHG emissions is de minimus ${ }^{2}$.

The US Government, through the Environment Protection Agency (EPA, 2009), operates a Climate Leaders Partners programme, in which companies are invited to make commitments to their reductions in GHG emissions (see Table 4) ${ }^{3}$.

\section{Upstream emissions}

The wide variations in reported emissions seem likely to arise from different approaches to accounting for inputs such as electricity, travel and emissions embedded in purchased equipment and outsourced services, pointing to the requirement to adopt standard methods for the assignment of GHGs. There are no generally agreed accounting principles for emissions, which is essential for complex sectors such as banking, health, retailing and telecommunications.

Given their heavy reliance on purchased goods and services, leading telecommunications operators and manufacturers are already looking at ways in which they can ensure "green" procurement. For example, some operators require contractors to certify compliance with ISO 14001. As a first step they have had to conduct reviews of established purchasing

\footnotetext{
${ }^{1}$ While it submitted a report to CDP in 2007 América Móvil requested this not to be published.

2 http://www.cdproject.net/download.asp?file=CDP5_Qwest_AQ.doc

3 http://www.epa.gov/stateply/partners/index.html
} 
procedures, which has sometimes required the education of suppliers about GHGs and other environmental issues. Among the operators that are or are in the process of becoming ISO 14001 compliant are BT, France Telecom, Telefónica and Telenor.

The International Organisation for Standards (ISO) has been active in the areas of energy efficiency, the environment and GHGs since 1992 (see Table 5). There is also work on LCA being undertaken by the Joint Research Centre of the EC, this will develop a reference life cycle database with inventory data sets, an internationally harmonized handbook to provide technical guidance for LCA and an information hub to knowledge exchange (JRC, 2009). It has already conducted a major consultation on life cycle analysis documents.

Table 5 - ISO standards for environment and GHGs

\begin{tabular}{|c|l|}
\hline Number & \multicolumn{1}{|c|}{ Short description } \\
\hline ISO 14001 & $\begin{array}{l}\text { Framework for the assessment of the environmental management of } \\
\text { products and services }\end{array}$ \\
\hline ISO 14040 & Life Cycle Assessment (LCA) \\
\hline ISO 14064 & Quantification and verification of GHGs \\
\hline ISO 50001 & $\begin{array}{l}\text { Framework for energy management in industrial plants, commercial facilities } \\
\text { and organizations. }\end{array}$ \\
\hline
\end{tabular}

The use of LCA in the evaluation of new technologies has made some progress (FRISCHKNECHT, 2009). In telecommunications, there is experience of its use across the full range of environmental factors, including the development of data sets to help in the application of LCA to future problems (SCHARNHORST, 2006).

One particular problem is cement, with a tonne of $\mathrm{CO}_{2}$ being emitted for every tonne of cement used, from chemical processes, heating and transportation (HUMPHREYS \& MAHASENAN, 2002). Thus any reduction in its use in telecommunications will generate significant emissions savings. For example, the cement used to fill holes dug in the road to install Fibre To The Home (FTTH) is a major part of the total GHG emissions for this service. If aerial cables, strung from poles, were to be used this could be greatly reduced, albeit at a cost to the visual environment. It is a choice and therefore a discussion which different communities can usefully contribute to, perhaps paying to offset any carbon dioxide emissions in return for burying the cables.

Mobile operators have begun a "green power" programme, examining the use of a range of technologies, including bio-diesel, fuel cells, pico-hydro, 
wind and photo-voltaic panels (GSMA, 2008). In the absence of mains electricity, one mobile operator in Africa is obliged to use 5 litres of diesel per customer per year. While this can gradually be replaced by photo-voltaic and other renewable sources, it is a capital intensive process. Given that investments are limited, there are choices in the speed at which a network is expanded, the rate at which customers' prices will fall and the installation of "green" power sources. Discussion of these issues with ministries, regulators and with the public will be important in ensuring optimal reductions in emissions per customer, in addition to any efficiency gains.

Equipment can be made less sensitive to temperature, by the widening its operational range, this reduces energy consumption in and can even eliminate the need for some heating and air-conditioning systems. However, if the effect of this is to accelerate the replacement of equipment then it may increase the costs for customers and generate more waste that must be recycled. One danger is that is simply refurbished and shipped from a developed to a developing country where it will continue to be inefficient but cheap. The economic and environmental trade-offs in telecommunications services have seldom, if ever, been made explicit to customers and to policy-makers. Yet, this is a pre-requisite in order that they can understand the choices they are already making and will have to make in the future.

\section{Downstream emissions}

The substantial increase in GHGs that comes with the growing use of telecommunications is argued to be only a fraction of the savings that can be achieved by organizations using the products and services that the sector supplies. As with concerns about purchased inputs, the attribution of the benefits from services sold is a matter of difficult accounting. The corporations and other organisations paying for telecommunication services will certainly claim any associated reductions in their GHG emissions, rather than allowing them to be taken by a telecommunications operator. For example, homes and businesses will want all the benefits from smart meters, though the electricity generators will also wish to claim a share, to help offset their emissions. Moreover, there will often be service providers and systems integrators as intermediaries who will lay claim to the savings. The need for organisational and personal changes and the methodology of ISO 14001, both suggest that the savings are attributable to the end user. 
For organizations that use telecommunications, detailed information is required to evaluate energy use and GHG emissions. They require tools for: Cost Benefit Analysis (CBA); Total Cost of Ownership (TCO); and Life Cycle Assessment (LCA). These would allow the calculation of the GHG and energy costs of, for example, a corporate IP-VPN per port or a "fleet" of mobile telephones per device. This information is essential to allow informed purchasing decisions. Corporate levels of GHG emissions need to be converted into data as input for ISO 14001 and 14064 analyses by customers so that they can identify where they can make their own savings.

In the case of large organizations, the primary mitigation of GHG emissions from ICTs is expected to come from the wider adoption of telework and teleconferencing. However, experience from recent decades suggests that there are significant obstacles, since adoption relies on a sequence of often difficult changes in organizational and personal behaviour. There are problems of homes unsuited for telework for any significant period of time and of managers who are less trustful of workers so employed. The result will be significant delays and differences between countries and between economic sectors. It requires work by business and government to develop guidelines, examples of best practice and calculations of savings. For example, NTT has adopted dress codes which permit greater informality which allow savings in cooling in summer and heating in winter.

For consumers there are, as yet, no standards to determine the energy efficiency or GHG emissions of the services they might buy, such as mobile telephony, fixed broadband and VolP. Given their wide range of choice, they are unable to make informed decisions. This is in contrast to electronic devices and consumer durable goods for which there are labels giving their energy efficiency and systems to ensure they are recycled. There is a serious problem of the growing profusion of devices in households in developed economies, many drawing significant power in standby mode.

Under the banner of electrical energy efficiency $\left(\mathrm{e}^{3}\right)$, the International Electrotechnical Commission (IEC) has been developing standards for a very wide range of devices. It has recently launched IEC 62301, to measure the standby power of household electrical appliances. There are also a range of national standards, often under the Energy Star brand.

The European Union adopted a Directive 2005/32/EC to address the performance of energy using products. The EC has adopted regulations which will implement significant savings to a wide range of devices (see Table 6). 
Table 6 - Energy consumption and savings from EU regulations

\begin{tabular}{|l|l|l|l|l|}
\cline { 2 - 6 } \multicolumn{1}{c|}{} & 2005 & 2005 & 2020 & Estimated savings \\
\cline { 2 - 6 } \multicolumn{1}{c|}{$\begin{array}{l}\text { standby and off mode power consumption of } \\
\text { electrical and electronic household and office } \\
\text { equipment }\end{array}$} & 19 & 47 & 49 & 35 \\
\hline external power supplies & & & & \\
\hline simple set-top boxes & 6.8 & 17 & 31 & 9 \\
\hline
\end{tabular}

$\left.{ }^{*}\right)$ To be achieved by 2014 .

\section{Conclusion}

The first challenge is to achieve a consistent basis for the assessment of green house gas emissions associated with telecommunications services. This is essential in order that manufacturers, operators and users can work systematically to understand, to contain and to reduce their growing effect on the climate.

The reporting by operators and manufacturers has advanced enormously in the last three years. Yet it is inconsistent and unaudited, making improvements difficult to verify. The lack of consistency in the data being reported means that generally agreed accounting principles are required for green house gases in order that emissions can be correctly assigned between organizations. The ISO 14000 series of recommendations are the best starting point for this work. It is also essential for the identification of global best practice and for the presentation of data to consumers to allow them to make informed decisions. In the medium term, with consistent methodologies and a range of data, it will be possible to identify benchmarks for global best practice.

At the policy and regulatory levels there is a need of methodology that includes GHG emissions and energy efficiency in the impact assessments made to support decision making. This would be an extension of existing methodologies, giving an appropriate weight to any differences in GHGs and energy consumption between the options presented to decision makers. With this it should be possible to ensure that policies encourage effective reductions in emissions and that the costs on a range of options are made explicit. 
For the consumer and the enterprise there are very few tools to help analyse the GHG inputs from their use of telecommunications. It is not yet possible to buy telecommunications with certified levels of GHG emissions.

The obligation from the Bali Action Plan and the Recommendation of the EC require the telecommunications sector to ensure that improvements are measured, reported and verified. This is a significant task and one requiring further work on methodologies and the collection of data. 


\section{References}

BIO-INTELLIGENCE SERVICES (2008): "Impacts of information and communication technologies on energy efficiency", Brussels: European Commission.

CDP (2009): http://www.cdproject.net/

CLIMATE GROUP (2008): "SMART 2020: Enabling the low carbon economy in the information age", Global e-Sustainability Initiative (GeSI).

COP (2009): available at http://www.cop15.dk/

DORAN, K., QUINN, E. \& ROBERTS, M (2009): "Reclaiming transparency in a changing climate: trends in climate risk disclosure by the S\&P 500 from 1995 to the present", Boulder: Center for Energy \& Environmental Security.

EC (2009): "Commission Recommendation on mobilising Information and Communications Technologies to facilitate the transition to an energy-efficient, lowcarbon economy", C(2009) 7604 final. Brussels: European Commission.

EPA (2009): Climate Leaders. http://www.epa.gov/stateply/partners/index.html

FRISCHKNECHT, F., BÜSSER, S. \& KREWITT, W. (2009): "Envionmental assessment of future technologies: how to trim LCA to fit this goa, International Journal of Life Cycle Analysis, 14 pp. 585-588.

GARTNER (2007): "Gartner estimates ICT industry accounts for 2 percent of global $\mathrm{CO}_{2}$ emissions". http://www.gartner.com/it/page.jsp?id=503867

GSMA:

- (2008): "GSMA launches renewable energy push for mobile networks", press release, 18 September 2008, London: GSM Association.

- (2009): "GSMA Research Shows Off-Grid Charging Solutions for Mobile Phones to Power US\$2.3bn Market Opportunity" press release, 20 October 2009, London: GSM Association.

HERZOG, T. (2009): "World greenhouse gas emissions in 2005", Washington DC: World Resources Institute.

HUMPHREYS, K. \& MAHASENAN, M. (2002): "Toward a sustainable cement industry: substudy 8: climate change", Geneva: World Business Council for Sustainable Development.

IEC (2007) "IEC = e3 = electrical energy efficiency: IEC initiates web project". Geneva: IEC.

IPCC (2007): "Climate change 2007: synthesis report", Geneva: Intergovernmental Panale on Climate Change. 
JRC (2009): See http://lct.jrc.ec.europa.eu/eplca

SCHARNHORST, W. (2006): "Life cycle assessment in the telecommunication industry: a review", International Journal of Life Cycle Analysis, 12, pp. 1-12.

WITOELAR, R. (2007): "The Bali Roadmap: address to closing plenary", Bali: UN Climate Change Conference. 